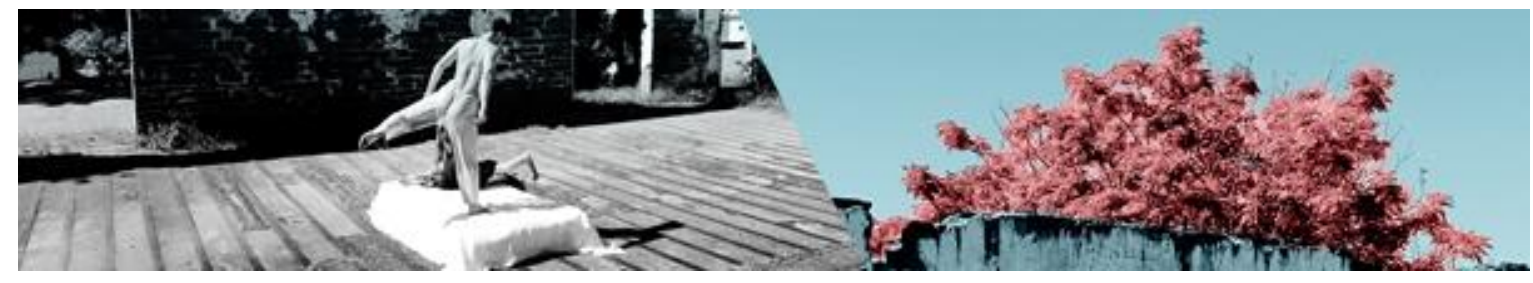

\title{
AS PAISAGENS DE PINA BAUSCH
}

\author{
Marcelo de Andrade Pereira ${ }^{1}$ \\ Maurílio Bertazzo Schuquel${ }^{2}$ \\ Ana Paula Parise Malavolta ${ }^{3}$
}

Resumo: O presente artigo de caráter ensaístico tem por objetivo refletir sobre conceito de paisagem a partir do trabalho da encenadora alemã Pina Bausch. Ao tomar a célebre artista como exemplo, o texto procura demonstrar a condição paradigmática que a sua produção exerce no âmbito da arte. Embora a paisagem resulte ou mesmo sintetize uma perspectiva, parte-se aqui do pressuposto que ela faz ver um todo. O marco teórico a partir do qual as noções de paisagem são aqui debatidas relaciona-se com o campo da antropologia, da geografia, das artes visuais e da filosofia.

Palavras-chave: Pina Bausch; Paisagem; Espaço.

\section{The Landscapes of Pina Bausch}

Abstract: The following article intends to discuss the concept of landscape through the work of German director Pina Bausch. Taking the famous artist as an example, the text seeks to demonstrate the paradigmatic condition that its production may represent for the art field. Although the landscape results or even synthesizes a perspective, the article assumes that the landscape makes see a whole. The theoretical framework from which the notions of landscape are discussed here is related to the field of anthropology, geography, visual arts, and philosophy.

Keywords: Pina Bausch; Landscape; Space.

\section{O Paradigma Pina: exemplos}

Este texto procura, por intermédio da reflexão acerca do conceito de paisagem, demonstrar a condição paradigmática da obra de Pina Bausch no campo da prática e do pensamento da arte. Por paradigma entendemos, à moda de Giorgio

\footnotetext{
${ }^{1}$ Professor do Programa de Pós-Graduação em Educação - linha educação e artes, UFSM; Coordena o FLOEMA, núcleo de estudos em estética e educação, da UFSM; Pós-Doutor pela NYU; Doutor em Educação, UFRGS; Mestre em Filosofia, UFRGS; Mestre em Educação, UFRGS; Graduado em Filosofia, UNISINOS; Editor Associado da Revista Brasileira de Estudos da Presença. Bolsista de Produtividade em Pesquisa CNPQ, nível 2. Atua na área de Estética e História das Artes, com pesquisa sobre Pedagogias Performativas e Pina Bausch.

2 Graduado em Artes Cênicas, UFSM. Mestrando em Artes Cênicas, UNB. Membro do FLOEMA Núcleo de estudos em estética e educação, UFSM.

${ }^{3}$ Graduada em Psicologia - URI. Mestre em Artes Visuais, UFSM. Doutoranda em Educação, UFSM. Membro do FLOEMA - Núcleo de estudos em estética e educação, UFSM.
}

PEREIRA, Marcelo de Andrade; BERTAZZO, Maurílio Schuquel; MALAVOLTA, Ana Paula Parise. As Paisagens de Pina Bausch. Revista da FUNDARTE, Montenegro, p.546-559, ano 19, № 37, Janeiro/Março.

Disponível em: http://.seer.fundarte.rs.gov.br/index.php/RevistadaFundarte/index> 30 de março de 2019. 


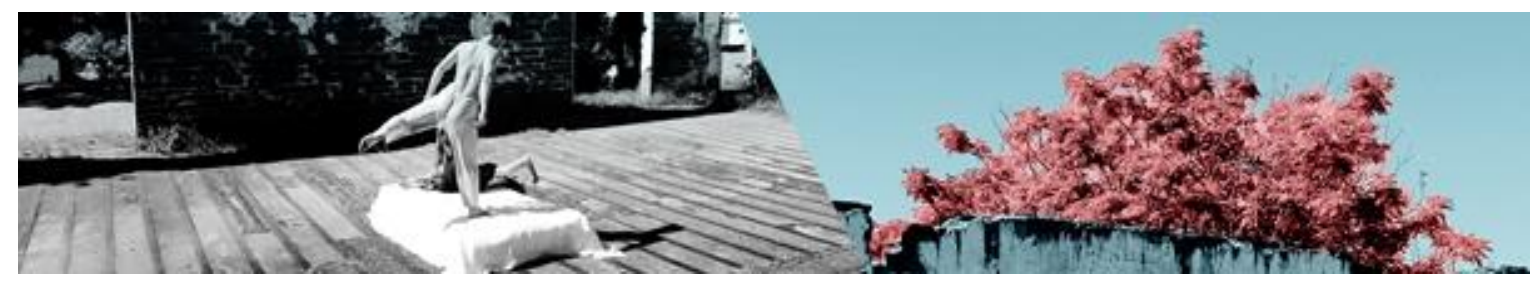

Agamben de Signatura Rerum, um "fenômeno histórico singular que define um contexto problemático mais amplo, que o constitui e se torna inteligível" (AGAMBEN, 2010, p.23).

Como sendo um paradigma, a produção de Pina, vista desde a ideia da paisagem, serve-nos aqui como um exemplo - e não precisamente uma metáfora -, isto é, como algo que nos permite compreender questões que se espraiam para além de um universo particular, de uma perspectiva situada e restrita sobre algum elemento ou algum lugar. Acerca disso, podemos salientar dentre a longa produção de Pina Bausch, as peças criadas em parceria com cidades de todo o globo, decorrentes das célebres residências artísticas, obras pertencentes àquela que poderia ser chamada por fase migratória do Tanztheater Wuppertal. ${ }^{4}$

Com efeito, sabe-se que desde o ano de 1986, com a produção de Viktor, até o ano de sua morte, em 2009, com a criação de Como el musguito en la piedra, Pina recorreu à diferente cidades para tanto cooptar recursos financeiros quanto materiais poéticos, procurando dar continuidade à sua investigação sobre a condição humana

\begin{abstract}
${ }^{4}$ Por fase migratória entendemos o período da produção de Pina Bausch no qual preponderam as coproduções, isto é, as peças criadas por intermédio de residências artísticas, em parceria com cidades do mundo inteiro. Embora se possa dizer que essa fase seja circunscrita pelo período de 1986 a 2009, não se pode afirmar que todos os espetáculos criados nesse mesmo interstício possam ser tomados como pertencentes a mesma fase. Fazem parte da fase migratória as obras Viktor (Roma, 1986); Palermo Palermo (Palermo, 1989); Tanzabend II (Madri, 1991); Ein Trauerspiel (Viena, 1994); Nur Du (Only You) (Los Angeles, 1996); Der Fensterputzer (Hong Kong, 1997); Masurca Fogo (Lisboa, 1998); O Dido (Roma, 1999); Wiesenland (Budapeste, 2000); Água (São Paulo, 2001); Nefés (Istambul, 2003); Ten Chi (Saitama, 2004); Rough Cut (Seul, 2005); Bamboo Blues (Calcutá, 2007); Como el musguito en la piedra, ay si si si (Santiago, 2009). À fase migratória diferenciam-se outras duas na produção de Pina Bausch, uma fase coreográfica, de 1974 a 1976, em que Pina se utiliza de materiais literários, míticos e musicais pré-existentes, tais como Fritz (1974); Iphigenie auf Tauris (1974); Adagio - fünf lieder von Gustav Mahler (1974); Ich bring dich um die ecke (1974); Orpheus und Eurydike (1975); Wind von West (1975); Das Frühlingsopfer (1975); Die Sieben Tödsunden (1976); e uma outra fase, de 1977 a 1985, também chamada de introspectiva, em que são explorados por Pina temas "universais", medos, angústias e conflitos, em que constam Blaubart - Beim anhören einer Tonbandaufnahme von Béla Bartóks Oper "Herzog Blaubarts Burg" (1977); Renate wandert aus (1977); Komm tanz mit mir (1977); Er nimmt an der hand und führt sie in das Schloss, die anderen folgen (1978); Café Muller (1978); Kontakthof (1978); Árias (1979); Keuschheiteslegende (1979); 1980 - Ein stück von Pina Bausch (1980); Bandoneon (1981); Walzer (1982); Nelken (1982); Auf dem gebirge hat man ein geschrei gehört (1984); Two cigarretes in the dark (1985).
\end{abstract}

PEREIRA, Marcelo de Andrade; BERTAZZO, Maurílio Schuquel; MALAVOLTA, Ana Paula Parise. As Paisagens de Pina Bausch. Revista da FUNDARTE, Montenegro, p.546-559, ano 19, ํㅡ 37, Janeiro/Março.

Disponível em: http://.seer.fundarte.rs.gov.br/index.php/RevistadaFundarte/index> 30 de março de 2019. 


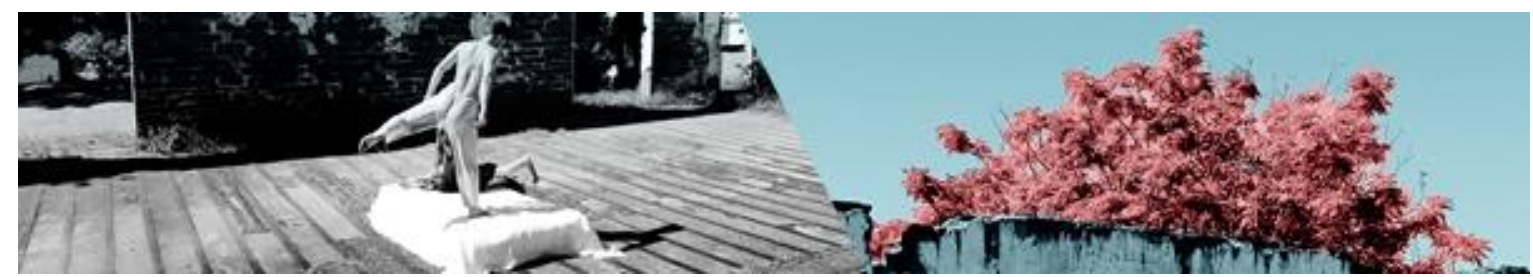

desde um determinado lugar. Uma das críticas mais recorrentes acerca dessa modalidade de produção - o das residências artísticas - seria a de que Pina não retratava de forma acurada o modo como as pessoas verdadeiramente viviam, habitavam esses lugares. Pina não teria sido, por assim dizer, fiel àquilo que supostamente pretendia retratar. É consabido, também, que segundo a mesma Pina essa não era precisamente a sua intenção (MULROONEY, 2015; PEREIRA, 2018; PEREIRA, 2012).

Deirdre Mulrooney (2015) em seu texto Orientalism, orientation, and the nomadic work of Pina Bausch sublinha, a respeito das peças decorrentes das residências artísticas, que tais produções não poderiam ser tomadas apenas como uma parte específica do que foi criado por Pina, mas o paradigma representativo de toda a sua estética e metodologia. Por se situarem justamente na perspectiva do trânsito, do deslocamento, é que as mesmas se apresentam como ambíguas e paradoxais. Como paisagens criadas que são - e não meros retratos -, as peçaspaisagens de Pina se apropriam da impossibilidade da apropriação, permitindo cada uma à sua maneira compreender uma totalidade - ainda que singular ou singularizada - de um ser em um lugar e do lugar em um ser. No ethos-paisagem de Pina, evidencia-se, pois, mais uma geografia dos afetos, dos relevos emocionais de um indivíduo perante o mundo das coisas e as coisas do mundo, do que precisamente dados concretos ou históricos de um dada localidade, de uma história ou de uma cultura particular (PEREIRA, 2012). Em Pina, a paisagem opera mais como uma síntese dramática das qualidades presentes em um espaço e no que esse espaço dá a ver, sentir e pensar, do que propriamente um quadro a ser esquadrinhado, uma quantidade a ser mensurada ou uma história ser verificada.

Como sendo paisagem, a perspectiva adotada por Pina opera, portanto, como um vetor que torna possível vislumbrar um todo pela parte. E é por força dessa condição que a obra de Bausch se torna exemplar. Como exemplar, ela pode ser, como bem nos lembra Agamben, tanto algo a ser apreciado pelos sentidos, quanto 


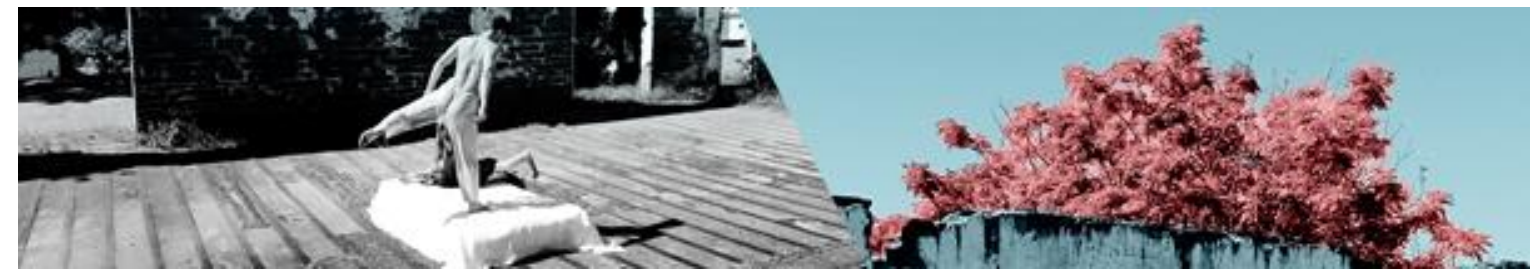

imitado por eles, exigindo, por sua vez, uma valoração mais complexa que a meramente sensível, qual seja moral e intelectual (AGAMBEN, 2010, p.24).

$\mathrm{Na}$ paisagem, Pina mostra o que observa e observa o que nos mostra. Para que possamos observar de maneira mais acurada o problema da paisagem na produção de Pina Bausch, vejamos de que maneira se montou histórica e filosoficamente esse conceito, atentando aos exemplos.

Um breve olhar sobre a (história da) paisagem

Como ambiente vivido e/ou captado pelo olhar humano, a paisagem, de alguma maneira, sempre existiu junto com os seres humanos, levando ora à utilização prática de seus recursos, ora à contemplação. Como aspecto visual, a concepção de paisagem como método de abordagem de um espaço geográfico, teve início em fins do século XIX. Como raízes deste pensamento pode-se mencionar as ideias da Antropogeografia de Friedrich Ratzel, sobre relações causais existentes na natureza, vindo depois o russo Vasily Dokoutchaev, com o modelo Complexo Natural Territorial (CNT), identificando as estruturas da natureza (SEGAUD, 2016).

No século XX, Carl Sauer apresentou suas ideias sobre estruturas da paisagem, enquanto Carl Troll elaborou a ecologia da paisagem, que associava a perspectiva horizontal geográfica com a perspectiva vertical da ecologia, em 1930. Já, Viktor Borisovich Sotchava, na Rússia, na década de 1960, formulou os geossistemas, com classes diferenciadas e similares da paisagem. Estes pensamentos, associados à história e cultura de suas respectivas épocas e lugares, foram fundamentais para a construção de ideias da paisagem como método de pesquisa ou forma de abordagem de um ambiente geográfico.

Ao sintetizarmos essas noções elementares de paisagem de épocas e áreas distintas de conhecimento, faz-se possível deslindar alguns aspectos que merecem especial atenção quando do estudo da paisagem, tais como: o aspecto visual; a PEREIRA, Marcelo de Andrade; BERTAZZO, Maurílio Schuquel; MALAVOLTA, Ana Paula Parise. As Paisagens de Pina Bausch. Revista da FUNDARTE, Montenegro, p.546-559, ano 19, nํ 37 , Janeiro/Março.

Disponível em: http://.seer.fundarte.rs.gov.br/index.php/RevistadaFundarte/index> 30 de março de 2019. 




complexidade de inter-relações entre os elementos físicos e destes com os elementos culturais; a possibilidade de cartografar a paisagem, já que a mesma ocupa um lugar; a diversidade da escala da paisagem - do local ao planetário; a possibilidade de classificar paisagens em unidades diferenciadas ou homogêneas; a possibilidade de classificar paisagens tanto com ênfase em um elemento de sua composição - vegetação, clima ou cultura - ou em seu caráter dinâmico; e a possibilidade de análise por meio dos elementos, estrutura e/ou funcionamento da paisagem (CAVALCANTI e VIADANA, 2007).

Assim, a paisagem em um contexto antropogeográfico se apresenta como o produto das interações entre elementos de origem natural e humana, em um determinado espaço. Estes elementos de paisagem organizam-se de maneira dinâmica, ao longo do tempo e do espaço, resultando daí feições e condições também dinâmicas, diferenciadas ou repetidas, o que permite uma classificação, ao agrupar os arranjos similares, separando-os dos diferentes. Este processo poderá ser tão detalhado ou amplo, quanto interessante ao observador. Vale ressaltar, portanto, que, dentro desse contexto enunciativo, paisagem não significa o mesmo que espaço geográfico, mas pode ser compreendida como uma manifestação deste. O espaço é o objeto de estudo da geografia, enquanto a paisagem poderia ser entendida como uma medida multidimensional de compreensão de um lugar (MAXIMIANO, 2004).

Em semelhante acepção, podem ser encontradas as reflexões do antropólogo brasileiro Milton Santos acerca da diferenciação entre Paisagem e Espaço; para Santos, a paisagem está sempre associada à produção do espaço (1996). Ao pensar no conceito de paisagem, Santos entende que

Tudo aquilo que nós vemos, o que nossa visão alcança, é a paisagem. Esta pode ser definida como o domínio do visível, aquilo que a vista abarca. Não é formada apenas de volumes, mas também de cores, movimentos, odores, sons, etc. (SANTOS, 1996, p. 61).

PEREIRA, Marcelo de Andrade; BERTAZZO, Maurílio Schuquel; MALAVOLTA, Ana Paula Parise. As Paisagens de Pina Bausch. Revista da FUNDARTE, Montenegro, p.546-559, ano 19, no 37 , Janeiro/Março.

Disponível em: http://.seer.fundarte.rs.gov.br/index.php/RevistadaFundarte/index> 30 de março de 2019. 


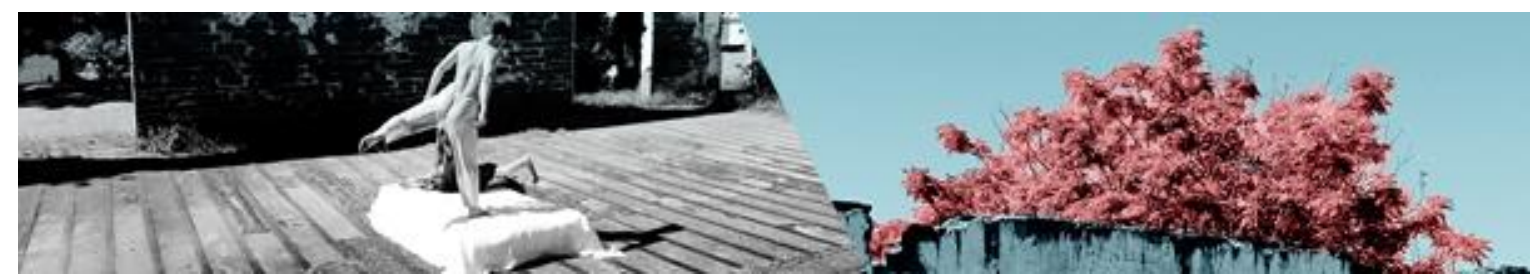

No entendimento de Santos, a paisagem diz respeito fundamentalmente à percepção de algo pelo olhar; ou seja, a paisagem acontece entre o espaço e o olhar de quem observa. Tal definição nos permite, pois, compreender a paisagem como um movimento da ordem do subjetivo, do singular e do acontecimento, concepção essa que já se encontra como que prenunciada na obra de Martin Heidegger (2002) quando esse discorre sobre o espaço. Em uma de suas célebres proposições acerca da Origem da Obra de Arte, Heidegger situa o espaço a partir de uma conhecida pintura de Van Gogh, O par de sapatos (1886). De acordo com o filósofo (HEIDEGGER, 2002), ao olhar para o par de sapatos, o sujeito estaria construindo simbolicamente outra paisagem sobre a terra e o caminhar, porquanto ao ver o seu entorno o sujeito seria capaz de, ao mesmo tempo, resguardar a representação da imagem da paisagem e construir em um entretempo de olhar uma outra paisagem. Nesse processo, segundo o filósofo, o sujeito estaria experimentando o "acontecimento da verdade", que, como qualquer acontecimento, seria de natureza essencialmente temporal e, portanto, dependeria de forma igualmente essencial de um lugar ou de um olhar, para acontecer. ${ }^{5}$

Ideia similar pode também ser verificada na antropologia de Lévi-Strauss, para quem a paisagem pode ser percebida e servir como entrada a diferentes experiências de entorno. Os efeitos dessa perspectiva para a abordagem histórica foram certamente familiares a ele, visto que o que esta categoria poderia elucidar seriam "modalidades" de conceber o entorno, e que, longe de se restringirem a determinadas épocas e lugares, poderiam ser surpreendidas nos mais variados contextos (LÉVI-STRAUSS, 2008).

Nas cercanias ainda da filosofia, Giorgio Agamben (2015, p. 84) observa que por intermédio do desdobramento simbólico da imagem, "o olho que olha se torna o olho olhado, e a visão se transforma em um ver-se a ver". Logo, pode-se concluir

\footnotetext{
5 Uma investigação de viés heideggeriano sobre o problema da verdade e do acontecimento na produção de Pina Bausch pode ser encontrada no artigo $O$ sentido da verdade e da linguagem em Pina: um estudo criacional, de autoria de Renata Tavares (2018).

PEREIRA, Marcelo de Andrade; BERTAZZO, Maurílio Schuquel; MALAVOLTA, Ana Paula Parise. As Paisagens de Pina Bausch. Revista da FUNDARTE, Montenegro, p.546-559, ano 19, no 37, Janeiro/Março.

Disponível em: http://.seer.fundarte.rs.gov.br/index.php/RevistadaFundarte/index> 30 de março de 2019.
} 


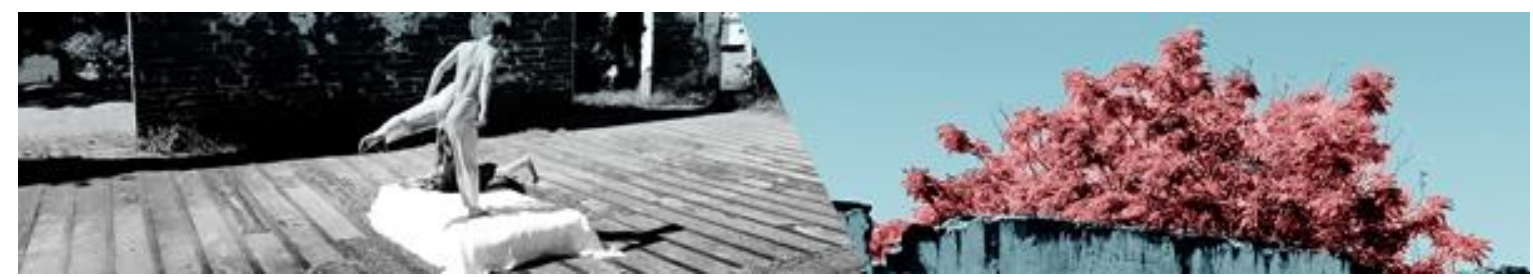

que a paisagem acontece no olhar, de modo movente e inacabado. Tal condição torna a paisagem algo de natureza eminentemente política, pois acontece pelos puros meios de olhar, em uma relação de gestos e campos. Dito de outro modo, a paisagem estaria no entremeio do campo e do observador; ela seria, por assim dizer, o fruto de uma intermediação. Desse modo, a paisagem acontece, como nos diria Agamben, por meio de uma política-que-vem, cuja potência não pode ser detida, porquanto é aberta à possibilidade da inoperância, da desativação das programações de um tipo de racionalidade que tem na utilidade e na efetividade seu grande norte.

Se por ventura possamos conceber a paisagem como algo de ordem política, que se desenvolve desde um olhar político, ligada à experiência e ao acontecimento, não se pode mais atrelá-la apenas às proposições sobre um estado de coisa, a delimitação de um espaço ou uma situação histórica. Neste pensamento, a paisagem nada teria a ver com um estado, mas com um acontecimento genuinamente político, de uma imagem e sua representação efetuadas no entretempo do olhar; a paisagem, portanto, operaria como um "olhar que vem", sendo concebida como uma experiência concernente à matéria e sua visualidade, ou à potência do pensamento.

À luz de uma reflexão estética, por exemplo a de Anne Cauquelin (2007, p.16), a paisagem pode ser tomada como um "conjunto de valores ordenados em uma visão", e possibilita que se aborde o espaço por meio de diferentes perspectivas como, por exemplo, o uso de tecnologias (visuais e sonoras). A paisagem corrobora ainda com outras modalidades de formação, relacionadas à processos de ver e de sentir, de apreensão da realidade do mundo e de concretização de valores culturais.

O processo de gênese da paisagem dentro desse diapasão conceitual também põe em cheque a ideia de que a paisagem está necessariamente ligada à natureza ou a uma categoria artística (uma pintura), pois seu nascimento diz respeito, antes de tudo, a um sistema de percepção: a perspectiva (um PEREIRA, Marcelo de Andrade; BERTAZZO, Maurílio Schuquel; MALAVOLTA, Ana Paula Parise. As Paisagens de Pina Bausch. Revista da FUNDARTE, Montenegro, p.546-559, ano 19, nº 37, Janeiro/Março.

Disponível em: http://.seer.fundarte.rs.gov.br/index.php/RevistadaFundarte/index> 30 de março de 2019. 




procedimento mental). Para Cauquelin (2007), a paisagem é um dos modos de convocar a natureza e a pintura, por sua vez, consiste na intermediação da relação do homem com o mundo; a paisagem é uma forma complexa da experiência ordinária. Ou seja,

De fato, parece que a paisagem é continuamente confrontada com um essencialismo que a transforma em um dado natural. Há algo como uma crença comum em uma naturalidade da paisagem, crença bem arraigada e difícil de erradicar, mesmo sendo ela permanentemente desmentida por numerosas práticas. (CAUQUELIN, 2007, p. 8).

Cauquelin (2007) assinala ainda que seria impossível determinar precisamente em um contexto histórico o nascimento da paisagem, de modo que, esse processo de aparecimento se fez por meio de infinitos desdobramentos. Todavia, a autora se arrisca e aponta que a paisagem teria nascido por volta de 1415, na Holanda, tendo passado pela Itália e então se espalhado pelo mundo. 0 aparecimento da paisagem se deu timidamente, para depois se afirmar. Sabe-se, com efeito, que as leis da perspectiva resultaram no surgimento da paisagem como arte pictórica. Na pintura, contudo, a paisagem estaria destinada a seduzir o espectador por meio da perspectiva, da harmonia dos elementos naturais emoldurados e da criação de uma realidade própria ao quadro. Foi com o passar do tempo que a paisagem, ao fim e ao cabo, deixou de ser apenas ornamento ou decoração e passou a ter uma realidade autônoma, para além da realidade do quadro.

Para inventar uma paisagem, lembra-nos Cauquelin (2007, passim), é preciso inicialmente ver o todo: observar a relação das coisas com as outras coisas, da montanha com as árvores, da casa com o campo. Entre os elementos que compõem a paisagem há uma harmonia que deve ser observada, sentida.

A paisagem é, por certo, uma evidência dada, oferecida aos sentidos, uma fruição que acontece entre o homem e o mundo. O que ajuda o sujeito a reconhecer a paisagem (como bela, por exemplo) são operações que dizem respeito a Janeiro/Março.

Disponível em: http://seer.fundarte.rs.gov.br/index.php/RevistadaFundarte/index> 30 de março de 2019. 


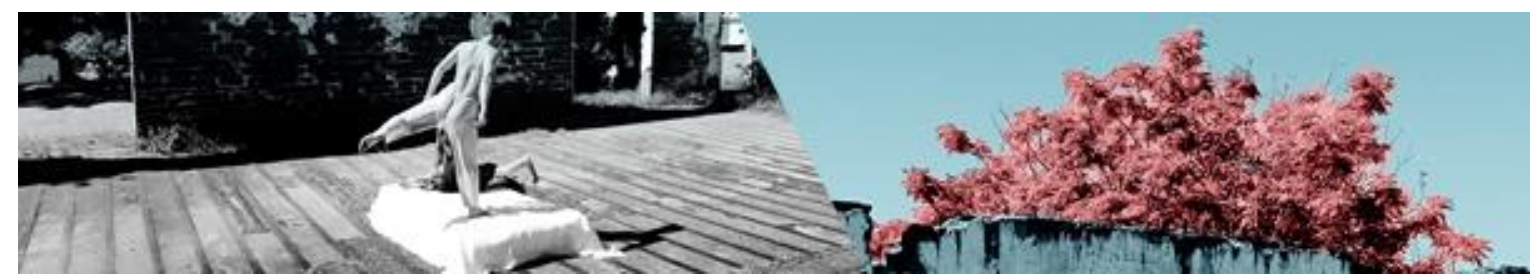

condições de sua própria cultura. Isso explica porque a satisfação decorrente da paisagem seja do âmbito da retórica, isto é, faz parte de um complexo de operações que transportam os objetos para uma forma simbólica, que passa "da realidade à imagem"; quem olha para uma paisagem crê enxergar aquilo que esperava, e não percebe a "obra" a sua frente, não se abre a possibilidade de produzir juízos estéticos (CAUQUELIN, 2007, p.118-119).

A janela, por exemplo, é um dispositivo pelo qual se percebe a paisagem. $O$ molde da janela corta, recorta, recua aquilo que é excedente; a moldura faz demarcar um fragmento em sua totalidade para ver a natureza em seu conjunto. A janela é um "instrumento paisagístico por excelência" (CAUQUELIN, 2007, p.138). Mas a paisagem continua para além da moldura, há um horizonte, "existe uma outra face da montanha" (CAUQUELIN, 2007, p.140). A paisagem, segundo Cauquelin (2007), guarda o potencial de análagon, pois se não fosse assim, ela seria apenas um simples simulacro.

Em decorrência de uma tradição (que excluí o que não é belo, harmônico), e que acabou por fixar os lugares, surge a necessidade de usar outros recursos da língua para que assim possam ocorrer transformações, ampliando o número de objetos que integram a descrição e a apreensão de uma paisagem. Para Caquelin (2007), a metáfora é um desses recursos. Por intermédio dela, constrói-se um conjunto, uma ligação entre os elementos. A metáfora transforma, modifica as formas. Sem essas associações, o sujeito não poderia ver para além daquilo que está à sua frente e, dessa maneira, não teria acesso a esse sentimento infindo da paisagem. Além do mais, "não teria[...]referência comum alguma para designar [seu] ambiente, ampliar seus limites, passar de um objeto a outro" (CAUQUELIN, 2007, p. 160).

Para Michel Collot (2013), a paisagem parece oferecer uma excelente ocasião para se exprimir uma "poética da relação". Neste entorno, como lugar de troca, onde se reencontram e se confrontam diferentes pontos de vista - uma espécie de ágora -, a paisagem apresenta uma implicação política de extrema PEREIRA, Marcelo de Andrade; BERTAZZO, Maurílio Schuquel; MALAVOLTA, Ana Paula Parise. As Paisagens de Pina Bausch. Revista da FUNDARTE, Montenegro, p.546-559, ano 19, no 37 , Janeiro/Março.

Disponível em: http://.seer.fundarte.rs.gov.br/index.php/RevistadaFundarte/index> 30 de março de 2019. 


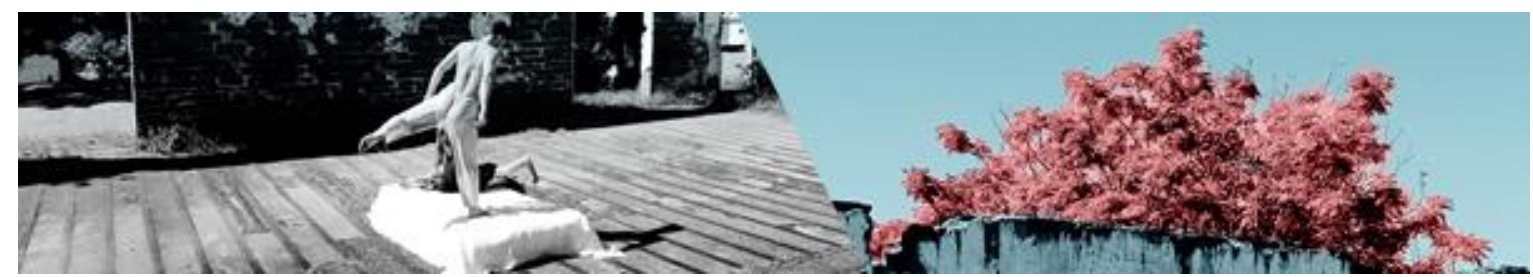

importância. A função da geografia é destacada na medida em que cumpre a gestão e a representação do meio para evolução dos indivíduos e sociedades. Depreendese, portanto, que, para contribuir com uma das noções mais essenciais da civilização atual - a paisagem -, a Geografia deve levar em conta a espacialização da atividade e do pensamento humano ao longo do tempo. Afinal, "vivemos, sentimos, criamos, pensamos no espaço e com ele, como também no tempo" (COLLOT, 2013, p. 198).

Pensa-se com Collot (2013), que a paisagem é um campo percebido, ou seja, diz respeito mais a apreensão de um todo, de um conjunto, que de uma observação focada, direcionada a um único objeto, a qual envolveria três aspectos: o local, o olhar e a imagem. A paisagem seria, pois, um fenômeno, visto que é resultante da relação entre o local, a percepção e a representação. Ela não é uma simples presença, muito menos uma representação que se basta por si só, consiste na relação do sujeito com o mundo, de quem observa com aquilo que é observado, do geógrafo com o espaço natural e urbano, do espectador com a obra.

A partir desses pressupostos é que Collot desenvolve a concepção de um "pensamento paisagem", noção decorrente dessa relação do sujeito com a paisagem, com o mundo. Para ele (COLLOT, 2013, passim), a paisagem provoca o pensar e o pensamento se desdobra na forma de paisagem; da relação que se estabelece com a paisagem surgem ideias e estas fazem parte de toda uma construção social e cultural. Nesse sentido, o sujeito age sobre a paisagem e ela também, de alguma maneira, age sobre o sujeito, fazendo-o pensar, seja num sentido geográfico, ambiental, cultural, social ou artístico. Ao mesmo tempo, Collot alerta que o sentido atribuído a uma paisagem não depende necessariamente de uma análise intelectual dos elementos que fazem parte dela, mas de uma percepção sintética das relações que unem esses elementos. A paisagem é relacional, é uma "constituição simultânea", é um "ato de pensamento", é um "ato estético", é um ato que diz respeito ao sensível.

PEREIRA, Marcelo de Andrade; BERTAZZO, Maurílio Schuquel; MALAVOLTA, Ana Paula Parise. As Paisagens de Pina Bausch. Revista da FUNDARTE, Montenegro, p.546-559, ano 19, no 37 , Janeiro/Março.

Disponível em: http://.seer.fundarte.rs.gov.br/index.php/RevistadaFundarte/index> 30 de março de 2019. 




No horizonte da paisagem alguns elementos estão expostos ao olhar e ao gozo do observador, ao passo que outros se ocultam, pois, para além daquilo que é visível, há um invisível; há um espaço interno; ou, ainda, outro lado da montanha a ser deslumbrado. O pensamento-paisagem vai para além das dualidades usuais, "não é só as do sensível e do inteligível, do visível e do inteligível, mas também as do sujeito e do objeto, do espaço e do pensamento, do corpo e do espírito, da natureza e da cultura" (COLLOT, 2013, p. 25).

A paisagem não somente vai para além das dualidades costumeiras, ela também desconstrói as dicotomias entre o objeto e o sujeito, o eu e o outro, pois a relação que se estabelece é mediada pelo sensível, pelo jogo entre a subjetividade e as coisas do mundo; "o pensamento-paisagem é um pensamento partilhado, do qual participam o homem e as coisas" (COLLOT, 2013, p 29). A paisagem possibilita uma redefinição da subjetividade humana, que deixa de ser autônoma para se abrir ao que está de fora, à relação; ela trata de um "espaçamento do sujeito", uma expansão que revela outras dimensões para o sujeito, uma projeção do sujeito no espaço sujeito que se recusa a permanecer em si mesmo -, sujeito que deixa de ser uma identidade fechada em si mesmo e se abre para fora, para o outro (COLLOT, 2013, p. 31). A paisagem diz respeito, em suma, a uma forma de espacialidade do pensamento, de espacialidade humana; é sempre um aqui e um lá, e por mais que o horizonte possa impor limites à visão, esse limite é móvel, pois o olhar tem a possibilidade de se deslocar na e com a paisagem.

\section{Um retorno à paisagem de Pina}

A paisagem, tal como foi até aqui problematizada, não está necessariamente ligada à natureza ou ao âmbito urbano, de modo que corresponde mais a um "desfoque" de uma determinada escritura do que sua cópia fiel; ou seja, ela vem a ser um dispositivo percebido, no qual são agenciados de modo equivalente diversos elementos; ela diz respeito a um campo que é construído, experimentado, sentido, e PEREIRA, Marcelo de Andrade; BERTAZZO, Maurílio Schuquel; MALAVOLTA, Ana Paula Parise. As Paisagens de Pina Bausch. Revista da FUNDARTE, Montenegro, p.546-559, ano 19, no 37, Janeiro/Março.

Disponível em: http://.seer.fundarte.rs.gov.br/index.php/RevistadaFundarte/index> 30 de março de 2019. 


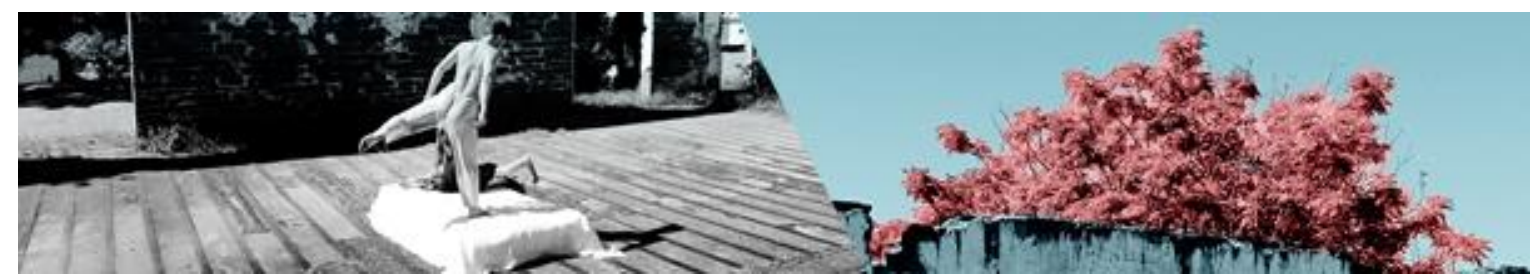

que escapa à ideia de um espaço comum e de um lugar específico. A paisagem está entre o espaço e o lugar; é a experiência do sujeito com o mundo que ele experimenta, reconstrói e ressignifica. Ela não se reduz à coesão entre um cenário, um figurino, uma forma de atuação e iluminação; ao contrário, associa-se a algo de ordem imaterial porque relaciona, num universo cênico, mais a atmosfera afetiva do que propriamente os elementos que compõem um "todo". Em Pina Bausch, o todo da paisagem exacerba a capacidade de esquadrinhamento pelo intelecto das partes. Michel Collot destaca justamente que "o sentido de uma paisagem não resulta de uma análise intelectual dos elementos que a compõem, mas de uma apreensão sintética das relações que os unem" (COLLOT, 2013, p. 23).

O conceito de paisagem opera aqui e na produção de Pina Bausch como uma noção capaz de criar estratégias de pensamento e de reflexão estética, que potencializa, como mencionamos anteriormente, uma espécie de "tonalidade afetiva" e relacional entre o sujeito e o mundo, o artista e o espaço, o espectador e a cena. A paisagem pode, por certo, como conceito geral, ter inúmeros modos práticos, geográficos, teóricos. Contudo, ela remonta à possibilidade de pensar a prática artística desde uma dimensão relacional - como prática relacional - entre o sujeito com o mundo, por intermédio dos sentidos, e do próprio mundo com o sujeito, por meio de uma materialidade imanente. A paisagem se irradia, portanto, desde a criação até a recepção - fazendo com que o próprio sujeito espectador se torne também criador, tomando parte do criado, tornando o criado, parte sua.

Em seu texto O teatro da experiência coreografado por Pina Bausch, Sayonara Pereira ressalta a característica relacional como inerente ao trabalho da encenadora alemã. Para ela, Pina constrói um "teatro no qual o espectador é envolvido em todos os seus sentidos, oferecendo condições de acolhimento". Nesse mundo criado por Pina, desenvolve-se uma dança com "conteúdo, com grafia própria, que convida o espectador a experimentar uma realidade poética" (PEREIRA, 2018, p.487). Como se pode observar, reverbera nessa passagem do ensaio de Pereira, os conteúdos que procuramos ao longo deste texto atribuir à PEREIRA, Marcelo de Andrade; BERTAZZO, Maurílio Schuquel; MALAVOLTA, Ana Paula Parise. As Paisagens de Pina Bausch. Revista da FUNDARTE, Montenegro, p.546-559, ano 19, no 37 , Janeiro/Março.

Disponível em: http://.seer.fundarte.rs.gov.br/index.php/RevistadaFundarte/index> 30 de março de 2019. 


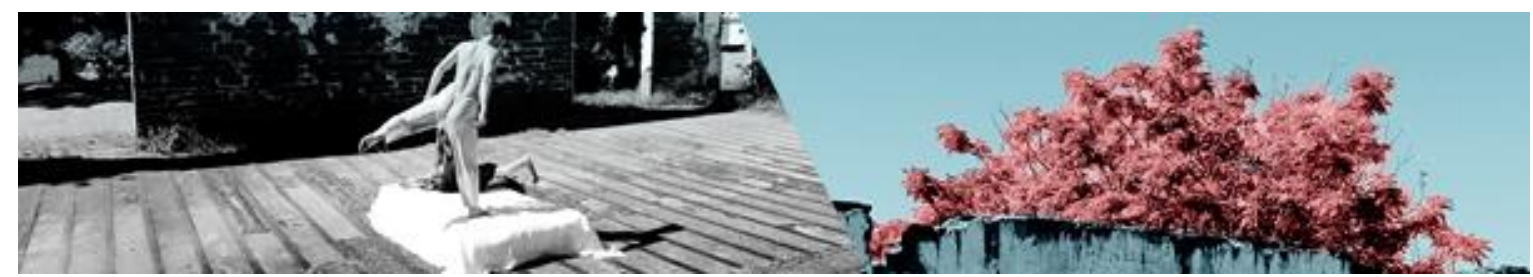

paisagem e que supomos verificar e reiterar a condição paradigmática e, portanto, exemplar, do trabalho de Pina Bausch - o que talvez permita explicar porque sua obra seja tomada tanto como matriz ética do trabalho de criação, quanto fonte de inspiração e/ou imitação. A amplitude da paisagem oferecida por Pina encoraja, de certo modo, tais formas de "apropriação" - que como as dela, apresentam-se também como ambíguas e paradoxais. Pina alargou as fronteiras entre as linguagens e, ao mesmo tempo, os limites dessas linguagens, para com isso possibilitar a visão de um universo de relações que não pode ser circunscrito, sequer pela linha da arte.

A beleza de sua produção reside, talvez, nessa condição de incerteza e inacabamento, de um registro de relações que implode as noções de propriedade, de "autoria, de individualidade, de representação e, em última instância, da própria linguagem" (TAVARES, 2018, p.522). O modo como o teatro, ou a dança-teatro, ou as paisagens de Pina - como quer que chamemos eufemisticamente sua produção - é construído a partir de uma subordinação da linguagem à verdade e à vida, ao acontecimento propriamente dito. O desenho em drama se expressa não só no palco sob a forma cotidiana dos jogos de poder entre homens e mulheres (como nas peças Viktor, Two Cigarretes in the Dark, em que mulheres são reduzidas à uma condição meramente animal), como também na repetição ad nauseam de gestos (como em Café Müller em que uma personagem despenca diversas vezes dos braços de um outro, como na morte por exaustação na dança de $A$ Sagração da Primavera), ou na simultaneidade de ações que descentraliza e cena e cria uma atmosfera de incerteza, de baralhamento e ao mesmo tempo de plenitude. Do todo que Pina nos permite ver pelas paisagens, sobra-nos, portanto, essa pequena parte:

Para ver é preciso saber olhar.

PEREIRA, Marcelo de Andrade; BERTAZZO, Maurílio Schuquel; MALAVOLTA, Ana Paula Parise. As Paisagens de Pina Bausch. Revista da FUNDARTE, Montenegro, p.546-559, ano 19, no 37 , Janeiro/Março.

Disponível em: http://.seer.fundarte.rs.gov.br/index.php/RevistadaFundarte/index> 30 de março de 2019. 


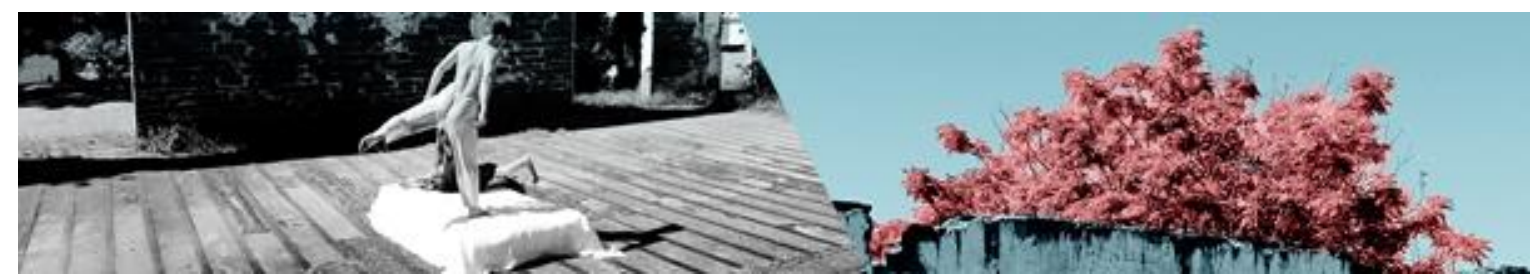

\section{Referências:}

AGAMBEN, Giorgio. Meios sem fim: notas sobre a política. Tradução de Davi Pessoa. Belo Horizonte: Autêntica, 2015.

AGAMBEN, Giorgio. Signatura Rerum: sobre el método. Barcelona: Annagrama Editorial, 2010.

CAUQUELIN, Anne. A invenção da paisagem. São Paulo: Martins, 2007.

CAVALCANTI, Agostinho; VIADANA, Adler Guilherme. Organização do espaço e análise da paisagem. Rio Claro: UNESP, 2007.

COLLOT, Michel. Poética e filosofia da paisagem. Rio de Janeiro: Oficina Raquel, 2013.

HEIDEGGER, Martin. A origem da obra de arte. Tradução Irene Borges Duarte. Lisboa: Fundação Calouste Gulbekian, 2002.

LÉVI-STRAUSS, Claude. Antropologia Estrutural I. São Paulo: Cosac Naify, 2008. MAXIMIANO, Liza Abad. Considerações sobre o conceito de Paisagem. Editora UFPR: Curitiba, n. 8, p. 83-91, 2004.

PEREIRA, Marcelo de Andrade. Entre e o relato e a paródia: Pina Bausch e suas releituras na pesquisa acadêmica brasileira. Revista Brasileira de Estudos da Presença, Vol.8, n.03, p.441-468, Jul/Set, 2018.

PEREIRA, Marcelo de Andrade. La spacialidad de los afectos en Pina Bausch. Telondefondo (Buenos Aires), n.16, p.205-216, 2012.

PEREIRA, Sayonara. O teatro da experiência coreografado por Pina Bausch. Revista Brasileira de Estudos da Presença, Vol.8, n.03, p.487-521, Jul/Set, 2018.

SANTOS, Milton. A natureza do Espaço: técnica e tempo, razão e emoção. São Paulo, SP. HUCITEC, 1996.

SEGAUD, Marion. Antropologia do espaço: habitar, fundar, distribuir, transformar. São Paulo: SESC São Paulo, 2016.

TAVARES, Renata. O sentido da verdade e da linguagem em Pina. Revista Brasileira de Estudos da Presença, Vol.8, n.03, p.522-538, Jul/Set, 2018. 